\title{
In vitro basal T-cell proliferation and HTLV-1 proviral load among HTLV-1 subjects co-infected with Hepatitis C and/or HIV-1
}

\author{
Tatiane Assone ${ }^{1,2^{*}}$, Tatiana Mitiko ${ }^{1 *}$, Samara PC Gomes ${ }^{1}$, Arthur Paiva ${ }^{1,2}$, Michel Haziot ${ }^{3}$, Jerusa Smid ${ }^{3}$, \\ Augusto Penalva de Oliveira ${ }^{3}$, Philip J Norris ${ }^{4}$, Jorge Casseb ${ }^{1,2^{*}}$
}

From 17th International Conference on Human Retroviruses: HTLV and Related Viruses

Trois llets, Martinique. 18-21 June 2015

\section{Background}

HTLV-1 infection may is present among HCV or HIVinfected subjects and is associated with higher risk for HAM/TSP and other inflammatory diseases. Lymphocytes from about half of HTLV-1-infected subjects spontaneously proliferate in vitro, and how this phenomenon relates to symptomatic disease outcome and viral burden is poorly understood. Objective: Evaluate T-cell proliferation in vitro and HTLV-1 proviral load (PVL) among co-infected subjects.

\section{Material and methods}

From 522 HTLV-1-infected individuals, who presented co-infection with HCV or HIV were selected during their outpatient visits to the HTLV clinic at the IIER in Sao Paulo. All the volunteers were invited to participate after reading and signing a consent form. Clinical data were obtained from medical records and interviews. PBMC from patients and controls, $2 \times 106$ cells $/ \mathrm{ml}$ in RPMI with $10 \%$ fetal calf serum were incubated at $37 \mathrm{C}$ and 5\% CO2 for 3 days in triplicate. Cells were pulsed with tritiated thymidine $18 \mathrm{~h}$ before harvest in a semiautomatic cell harvester and counted in a beta-counter. To determine the proviral load, the HTLV-1 DNA copy number was done by RT-PCR to the amount of the cellular albumin of the clinical sample, which was quantified in parallel. Results were expressed as HTLV-1 DNA copies/104 PBMCs. Statistical analysis was conducted using Kruskal-Wallis test.

\section{Results}

From a total infected with HTLV-1, 123 (24\%) subjects presented co-infection, where 81 had HIV-1 (15\%), 40 had HCV (8\%) and 37 had HIV-1 and HCV (7\%). The basal T-cell proliferation show an increase among $\mathrm{HCV} /$ HTLV-1 subjects compared to patients with HTLV-1/ HIV-1 co-infection and HTLV-1/ HIV-1/HCV ( $\mathrm{p}=0.1)$. The HTLV-1 PVL was also highest in the HTLV-1/ HCV subjects $(\mathrm{p}=0.6)$.

\section{Conclusion}

We observed a significant increase of basal T-cell proliferation among HTLV-1/HCV co-infected. However, the presence of co-infection with HIV-1 may induce a down regulation at T-cell proliferation capacity. Support: FAPESP 2012/23397-0.

\section{Authors' details \\ ${ }^{1}$ Laboratory of Dermatology and Immunedeficiencies, Department of Dermatology, University of São Paulo Medical School, Brazil. ${ }^{2}$ Institute of Tropical Medicine of São Paulo, São Paulo, SP, Brazil. ${ }^{3}$ Institute of Infectious Diseases "Emilio Ribas" (IIER) of São Paulo, São Paulo, SP, Brazil. ${ }^{4}$ Blood Systems Research Institute, San Francisco, California, USA.}

Published: 28 August 2015

doi:10.1186/1742-4690-12-S1-P17

Cite this article as: Assone et al: In vitro basal T-cell proliferation and HTLV-1 proviral load among HTLV-1 subjects co-infected with Hepatitis $\mathrm{C}$ and/or HIV-1. Retrovirology 2015 12(Suppl 1):P17.

\footnotetext{
* Correspondence: tatianeassone@usp.br

${ }^{1}$ Laboratory of Dermatology and Immunedeficiencies, Department of

Dermatology, University of São Paulo Medical School, Brazil

Full list of author information is available at the end of the article
} 